\title{
EDITORIAL
}

\section{Combining evidence and experience in pulmonary hypertension}

\author{
M. Humbert* and L.J. Rubin ${ }^{\#}$
}

$\mathbf{T}$ he term pulmonary hypertension $(\mathrm{PH})$ describes a group of devastating and life-limiting diseases, defined by mean pulmonary artery pressure $\geqslant 25 \mathrm{mmHg}$ at rest [1]. $\mathrm{PH}$ can be idiopathic in origin or can arise in association with a range of underlying causes. Clinical symptoms of progressive dyspnoea and decreasing exercise capacity, and the potential for the development of right heart failure, are common to all forms of $\mathrm{PH}$, despite the differences in aetiology. Presently, $\mathrm{PH}$ is classified clinically, with the various subgroups sharing similar clinical presentations and pathogenetics [2].

Pulmonary arterial hypertension (PAH) forms group 1 of this classification and is characterised by a progressive increase in pulmonary vascular resistance leading to right ventricular failure and premature death. Although we cannot yet claim a "cure" for PAH, recent advances in the use of targeted therapies have led to improvements in symptoms, exercise capacity and, in some cases, survival. Evidence also suggests that early management may improve outcome. Given such advances, early recognition and prompt and accurate diagnosis of $\mathrm{PH}$ and its underlying aetiology are of critical importance.

This issue of the European Respiratory Review features a series of articles and educational case reports written by experts in the field of $\mathrm{PH}$, based on presentations at two recent international meetings sponsored by Actelion Pharmaceuticals (Allschwil, Switzerland). The first of these meetings was the Third International Systemic Sclerosis Forum, which took place in Basel, Switzerland between February 28 and March 1, 2009, and was attended by 568 delegates, including physicians from 44 countries. The second of these meetings was the Eighth International Pulmonary Hypertension Forum in Barcelona, Spain, which took place on March 21-22, 2009, and was attended by 1,046 delegates, including physicians from 57 countries. The manuscripts in this issue present updates on the status of particular "hot topics" in $\mathrm{PH}$ that were considered

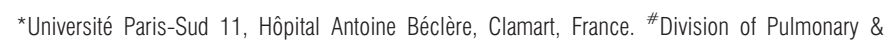
Critical Care Medicine, University of California, San Diego, CA, USA.

CORRESPONDENCE: M. Humbert, Service de Pneumologie, Hôpital Antoine Béclère, Assistance Publique Hôpitaux de Paris, Université Paris-Sud 11, 157 rue de la Porte de Trivaux, 92140 Clamart, France. E-mail: marc.humbert@abc.ap-hop-paris.fr

Received: June 12 2009; Accepted: June 122009

PROVENANCE: Publication of this peer-reviewed article was supported by Actelion Pharmaceuticals Ltd, Switzerland (unrestricted grant, European Respiratory Review issue 113). during these fora, including an evaluation of combination therapy regimens, the classification and management of $\mathrm{PAH}$ associated with congenital heart disease (CHD), and the need for screening for PAH in high-risk patient populations, such as people with systemic sclerosis (SSc).

Multiple pathophysiological pathways are implicated in the development of PAH [3], making a strong rationale for the use of combinations of different targeted drugs in its management. It is clear from available registry data that combination therapy regimens are increasingly commonplace, despite limited data from controlled clinical trials. Data from such trials are now emerging and support the potential benefits of combination therapy in PAH. In reflection of this, combination strategies are being included in new treatment guidelines [4]. Although the safety and cost implications of combination therapy may remain issues for some, these concerns may be addressed with the emergence of future data. In their review, GALIÈ et al. [5] provide an update on this important treatment consideration, describing data on various combinations of therapies, management strategies and outstanding issues that remain to be fully addressed.

The clinical course of patients with many forms of $\mathrm{CHD}$ is commonly complicated by PAH. Although previously seen largely in children, improvements in detection and surgical management have led to more patients with CHD surviving to adulthood, thus shifting demographics in PAH-CHD and presenting new challenges to the clinician. In this issue, GATZOULIS et al. [6] provide a seminal review of the pathophysiology, natural history, classification and diagnosis of paediatric and adult PAH-CHD, discussing current progress in this field, including recent data on targeted therapies.

Pulmonary complications in people with SSc are some of the most lethal in this vulnerable patient population. For SSc patients who develop $\mathrm{PAH}$, the prognosis can be particularly poor. Furthermore, due to the nonspecific and overlapping nature of their symptoms, patients with PAH associated with SSc often present late, when their pulmonary disease is at an advanced stage: a situation that undoubtedly contributes to morbidity and mortality. Evidence suggests that early management using targeted therapies may be beneficial in these patients and so strategies for improving early diagnosis are of increasing interest. In their expert review, VACHIÉRY and COGHLAN [7] examine the value of screening for $\mathrm{PAH}$ in patients with SSc, outline important considerations in patient selection and the choice of screening tools, discuss gaps in our 
current knowledge, and identify future directions for research and discussion.

Alongside these expert reviews, three interesting and informative case reports are presented, which emphasise potential issues and important considerations in managing patients with $\mathrm{PH}$. The first, presented by VizzA et al. [8], concerns a seriously ill patient with a pre-existing diagnosis of portopulmonary hypertension who was subsequently found to have severe $\mathrm{PH}$ associated with a previously unrecognised congenital heart defect. This case highlights the need to fully investigate alternative causes of symptoms to avoid misdiagnosis, and its subsequent life-threatening risks, in adult patients with an atypical presentation.

A case reported by KÄHLER [9] concerns an older patient with a complex medical history, including a diagnosis of chronic obstructive pulmonary disease and pulmonary embolism (PE). This patient's subsequent re-diagnosis of chronic thromboembolic pulmonary hypertension (CTEPH) is in keeping with evidence to suggest that, although generally considered to be rare, the association between CTEPH and PE may be more common than previously thought [10].

Pulmonary veno-occlusive disease (PVOD) is an under-recognised and often misdiagnosed disease, and is recognised as one of the more malignant forms of $\mathrm{PH}[11,12]$. PALAZZINI and MANES [13] describe the detection of PVOD in a young female with worsening dyspnoea who had been wrongly diagnosed as exhibiting idiopathic PAH. Such a misdiagnosis has potentially fatal implications with regard to treatment decisions. Although PVOD is notoriously unresponsive to medical therapy, new targeted therapies may, as in the case presented here, stabilise the disease and/or provide clinical improvement as a bridge to lung transplantation, which is generally the only long-term option for many of these patients [14].

These three case studies emphasise the importance of a full diagnostic work-up in patients with $\mathrm{PH}$, in whom classification and diagnosis of the underlying cause may be complicated by nonspecific, overlapping or unusual symptoms, but which is essential to ensure optimal management. Given the recent increase in data on the use of targeted therapies in $\mathrm{PH}$ and the awareness of the importance of early management, the expert articles and case studies in this issue of the European Respiratory Review provide a timely review of evidence and experience in some key areas in this field.

\section{STATEMENT OF INTEREST}

M. Humbert has relationships with drug companies including Actelion, Bayer Schering, GlaxoSmithKline, Novartis, Pfizer and United Therapeutics. In addition to being investigator in trials involving these companies, relationships include consultancy services and membership of scientific advisory boards. L.J. Rubin has relationships with drug companies including Actelion, GlaxoSmithKline, Pfizer, Gilead and United Therapeutics, with which he is also a stockholder. In addition to being investigator in trials involving these companies, relationships include consultancy services and membership of scientific advisory boards. L.J. Rubin has also acted as an expert witness on this subject.

\section{ACKNOWLEDGEMENTS}

Editorial assistance was provided by Elements Communications (Westerham, UK), supported by Actelion Pharmaceuticals Ltd (Allschwil, Switzerland).

\section{REFERENCES}

1 Badesch DB, Champion HC, Gomez Sanchez MA, et al. Diagnosis and assessment of pulmonary arterial hypertension. J Am Coll Cardiol 2009; 54: S55-S66.

2 Simonneau G, Robbins IM, Beghetti M, et al. Updated classification of pulmonary hypertension. J Am Coll Cardiol 2009; 54: S43-S54.

3 Humbert M, Sitbon O, Simonneau G. Treatment of pulmonary arterial hypertension. N Engl J Med 2004; 351: 1425-1436.

4 Barst RJ, Gibbs JS, Ghofrani HA, et al. Updated evidence-based treatment algorithm in pulmonary arterial hypertension. J Am Coll Cardiol 2009; 54: S78-S84.

5 Galiè N, Negro L, Simonneau G. The use of combination therapy in pulmonary arterial hypertension: new developments. Eur Respir Rev 2009; 18: 148-153.

6 Gatzoulis MA, Alonso-Gonzalez R, Beghetti M. Pulmonary arterial hypertension in paediatric and adult patients with congenital heart disease. Eur Respir Rev 2009; 18: 154-161.

7 Vachiéry J-L, Coghlan G. Screening for pulmonary arterial hypertension in systemic sclerosis. Eur Respir Rev 2009; 18: 162-169.

8 Vizza CD, Badagliacca R, Poscia R, et al. Unusual presentation for a patent ductus arteriosus. Eur Respir Rev 2009; 18: 174-176.

9 Kähler CM. Chronic thromboembolic pulmonary hypertension as a cause of dyspnoea in an older patient with a complex history. Eur Respir Rev 2009; 18: 170-173.

10 Pengo V, Lensing AW, Prins $\mathrm{MH}$, et al. Incidence of chronic thromboembolic pulmonary hypertension after pulmonary embolism. N Engl J Med 2004; 350: 2257-2264.

11 Montani D, Price LC, Dorfmuller P, et al. Pulmonary venoocclusive disease. Eur Respir J 2009; 33: 189-200.

12 Montani D, Achouh L, Dorfmüller P, et al. Pulmonary venoocclusive disease: clinical, functional, radiologic, and hemodynamic characteristics and outcome of 24 cases confirmed by histology. Medicine (Baltimore) 2008; 87: 220-233.

13 Palazzini M, Manes A. Pulmonary veno-occlusive disease misdiagnosed as idiopathic pulmonary arterial hypertension. Eur Respir Rev 2009; 18: 177-180.

14 Montani D, Jais X, Price LC, et al. Cautious use of epoprostenol therapy is a safe bridge to lung transplantation in pulmonary veno-occlusive disease. Eur Respir J 2009; [Epub ahead of print PMID 19541723]. 